\title{
The Effect of Corrective Feedback Strategies via Email on Writing Accuracy Improvement: A Case of Iranian EFL Learners
}

\author{
Farid Mousavi \\ University of Isfahan \\ Email: sfarid.m67@gmail.com \\ Amir Mahshanian \\ University of Isfahan \\ Email:mshn_amir@yahoo.com
}

\section{Doi:10.5901/ajis.2016.v5n3p149}

\begin{abstract}
Indubitably, The efficacy of feedback has received a great deal of attention in recent years. In this respect the importance of Corrective feedback in learning has taken the notice of scholars. There are various strategies of providing corrective feedback which are the aims of this present article. In addition, student writing in different contexts of ESL/EFL has heightened the need for this study, too. Accordingly, the present study aimed at investigating the provision of corrective feedback on student writing via new media of communication as Email and Microsoft Word software.To this end, from the population of 84 Iranian EFL students of higher intermediate levels, 4 groups of indirect feedback, direct feedback, indirect followed by direct with explicit corrective comments, and no feedback (IF, DF, IDECC, NF) were selected. These groups were observed concerning the impact of feedback each group received the results of this study are in line with the effectiveness of corrective feedback in student writing. The analysis of the data indicated that all three treatment groups achieved better results than the control group after two stages of revisions. Among treatment groups, the IDECC which received instruction of both strategies of providing feedback gained the most impact in the new essay and in a long run.
\end{abstract}

Keywords: corrective feedback, indirect feedback, direct feedback, explicit corrective comments, writing

\section{Introduction}

So much so the past two decades have witnessed a growing interest of feedback among many researchers and teachers. Taking a broader view of the concept, feedback plays a crucial role in the phenomenon of learning and it cannot simply be overlooked. A breif look at the literature available in second language acquisition and language teaching manifests disagreeing findings of feedback which need further investigation. the second or foreign language learning includes receptive and productive skills (listening, reading, speaking, and writing. With regard to the writing of ESL/EFL students, there have been empirical investigation focusing on various aspects of writing. Yet, student writing requires further research so as to improve their writtings.

The tendency of ideas in the field of English language teaching has swung back to the point that teachers and researchers once again are talking about the significant role of a real classroom context. A new direction of investigation is dealing with the role of feedback through new technologies. due to the fact that most of the students today have easy access to their emails on their laptops, smart phones, etc. they can be provided with feedback by their teachers, peers, etc. the majority of Iranian EFL students these days spend most of their time surfing the net, checking their emails, and taking part in social networks. Therefore, it was assumed that the role of feedback needs to be examined in their writing tasks via new means of providing feedback as email.

\section{Purpose of the Study}

The main objective of the present study is to explore the efficacy of written corrective feedback (WCF) and its various strategies by means of email and new technologies. Since previous studies have focused on one of feedback provision strategies at the time, this study considers a complementary strategy of providing feedback; i.e. feedback in two stages in a way the second strategy completes the first one. Moreover, there is a hunch that students would benefit the most if they 
are provided with both strategies of direct and indirect along with explicit corrective comments to make them better able to recognize the intended feedback.

According to the above-mentioned issues, the current study has certain research questions: 1) to what extend does the frequency of learners' on essay drafts vary as a result of teacher's type of corrective feedback (i.e., Indirect, direct, indirect followed by direct with explicit corrective comments, or no feedback), and 2) does the impact of providing feedback last longer after treatment?

In this study four strategies of providing feedback are taken into account to provide learners with feedback as Indirect Feedback (IF), Direct Feedback (DF), Indirect Feedback then Direct Feedback along with Explicit Corrective Comments (IDECC), and No Feedback (NF).

\section{Background}

In the new global professionalism in the domain of language teaching there have been many attempts for a long time to investigate the efficacy of feedback in language learning. Various theories in learning such as those of Behavioral, Cognitive Information Processing, Skill Acquisition, Interactionist, etc. have put strong emphasis on the role of feedback Bitchener (2012). Yet, findings of a number of research studies (e.g., Kepner 1991, Rob, Ross \& Shortreed 1986, Semke 1984, Sheppard 1992, and Sheppard1992) conclude that feedback is neither influential nor usefulness to students while doing their writing tasks. He further contended that the practice of providing feedback in student writing should be avoided and quit. Ferris (1999) in response to his claims, stated that Truscott may have not been attentive enough in drawing a line between the well-done studies and the poor ones, or that he may have neglected some points within such studies. Moreover, Guénette (2007) proposed that such contrasting results could be due to a couple of reasons including design, methodology, and external variables of the research. Thus, further studies are needed to reach a more decisive answer to such a sparked debate by these researchers.

With regard to the effectiveness of feedback, there are no definite answers to which feedback is better, but selective written feedback seems to be more effective to learners than comprehensive one. However, this seems to be true considering just one specific grammatical feature, like definitive articles. Recently, a positive trend to develop the research on providing feedback in a focused manner using metalinguistic explanation has been increasing Ellis, Sheen, and Murakami and Takashima (2008). The influence of written corrective feedback (WCF) on EFL learners' performance after completing output activities was examined by Abadikhah and Ashoori (2012). They conducted a study on intermediate EFL learners in two groups. In their study, editing the text, composing, transforming and substituting it were taken as output activities for two groups; one receiving WCF and the other suffering no WCF. Results indicated that the participants receving WCF after completing the activities outdid those who not receiving written feedback. They found that if learners are provided with corrective feedback they may become more aware of the differences in their interlanguage and the target language they are learning.

Azizi, Behjat, and Sorahi (2014) carried out a study within a process-oriented framework to determine the degree to which explicit corrective feedback may affect Iranian EFL learners' writing accuracy, and to make a comparison between the efficiency of two sorts of explicit corrective feedback, error codes feedback and description feedback on students' writing performance. Conducting the research study on 69 learners ( all female), they found that the metalinguistic teacher corrective feedback, especially along with describing points, had a positive effect on Iranian EFL learners' writing improvement.

As a further attempt to investigate the value of feedback in an online learning environment, In their study, Alvarez, Espasa, and Guasch (2012) explored the improvement of collaborative writing of university students in Spain. They aimed at analyzing the nature of teacher feedback during assignments. By e-learning and within a two-week period, 83 students were under examination. The results expressed that when the teacher-provided feedback involves questions and recommendations, instead of just explicit corrections, learners performed more constructively, they make discussions on the content they are dealing with. Such results may imply that explanation and other meta-linguistic tools to make students aware of their mistakes may be more efficient in helping learners improve their works after they are provided with due feedback.

A large and growing body of literature has been published to further explore the impact of metalinguistic explicit feedback and the efficiency of computer-mediated-communication (CMC) in aiding learners to develop their writing accuracy, AbuSeileek and Abualsha'r (2014) carried out a research study on sixty-four intermediate-level learners consisting of three treatment groups as recast, track changes, and metalinguistic feedback. Conducting research study over 8 weeks, they maintained that those students receiving CMC corrective feedback while doing writing tasks 
outperformed in their overall test scores than students in the control group not receiving feedback. Students in the recast treatment group also outdid compared to those who received metalinguistic corrective feedback.

More on metalinguistic feedback, Ebadi (2014) made an attempt to examine the influence of "focused Metalinguistic highlighted error feedback on accuracy of writing among Iranian intermediate students". After 12 sessions of treatment on 60 university students, they were exposed to focused meta-linguistic feedback on the submission of their essays. Once the analysis was done, it was found that experimental group who received metalinguistic feedback could outperform the control group.

Regarding the type of feedback and strategies by which learners are provided with, there have been abundant studies focusing on just one way or another. Indirect and direct strategies have been the concentration of certain previous research studies. Yet, there have been no controlled studies which accentuate the significance of complementary manner under investigation. In this line, Rahimi and Asadi (2014) conducted a study in order to investigate the long term influences of different types of feedback as indirect, direct, and content feedback on EFL learners' writing accuracy and overall writing quality. Three treatment groups were under investigation; indirect and direct receiving both formal and content feedback, but content group receiving just content feedback. Findings of their study revealed that there was a significant but scant difference between formal feedback groups (considered as direct and indirect) and just content group with respect to the long-term improvement observed in their writing accuracy. They also found that content feedback appears to be the most efficient method in providing feedback, when we deal with the long-term improvement accuracy of writing.

Ahmadi, Maftoon, and Gholami (2012) compared two types of feedback on EFL students' writing. Feedback groups as direct and un-coded one along with a control group were under investigation. $60 \mathrm{EFL}$ students took part in this study to write paragraphs on the assigned topics. Teacher feedback was found to be of high significance in aiding students to improve their writing accuracy. Also, better results were found on the un-coded feedback group in comparison to the direct one Jokar and Soyoof (2014) compared two Iranian EFL learners in terms of their writing accuracy after receiving implicit and explicit feedback. Two pre-intermediate learners of English in an institute were chosen to participate in a case study. Once they completed their tasks they were provided with implicit (for one of them) and explicit (for the other) feedback. Results of their study suggest that the group receiving explicit feedback could better absorb the grammatical points.

So far it has been revealed that various recently done studies attempted to concentrate on one or more aspects of writing with respect to the teacher corrective feedback. Certain studies dedicated to investigate the effectiveness of corrective feedback, with or without using new technologies. Some others considered the metalinguistic, direct, indirect, or other ways of providing feedback. Yet, there hasn't been an individual study dealing with a complementary manner of providing feedback via new means of communication to explore the efficiency of feedback on Iranian EFL learners.

Thus, in an attempt to examine the differences among treatment groups receiving their own feedback type and the group which receives the complementary manner of feedback, the present study takes into consideration, a new way of providing feedback in two stages (i.e., indirect feedback, and then direct feedback along with explicit corrective comments). This, also adds to the literature the effectiveness and importance of different strategies of corrective feedback. To shed more light, however, on the differences among different corrective feedback strategies, this study also has got its specific focus on provision of feedback via e-mail and its effect on learners' writing accuracy.

\section{Methodology}

To come up with suitable responses to the proposed research questions, a number of Iranian EFL learners from various English language institutes were asked to cooperate in this study. Since this study was to exert new technologies and examine the effectiveness of feedback by the help of such new means of providing feedback, all communications were made through emails. Students who were learning at higher intermediate levels were selected for participating in this study. They were asked to send their email addresses to the teacher. Once their emails were collected, they were sent an email consisting of a consent letter and a prompt to write a 300-word paragraph on their experience of learning English through previous years. Having consented, they sent their first narrative essays. Their writings were written by Microsoft Word software so that teachers could put their comments, which were considered as provision of feedback, on each intended grammatical error. Just three frequent English errors had been selected prior to the study; English articles, verb agreement, and question forms. Being randomly assigned, 84 students fulfilled the whole tasks. Writing tasks included 5 phases: Essay 1, Revised Draft 1, Revised Draft 2, Essay 2, and Delayed New Essay. Following is the description of how feedback was provided for students in their groups. 
In the first group (IF), learners were provided with two stages of indirect feedback, and they were permitted to revise their works after each feedback. A new essay was written in the fourth step to investigate the effectiveness of the feedback. To further investigate the longer impacts of feedback, a delayed new essay was written a month later after the last essay (essay 2). To see examples of this type of corrective feedback see appendix 1. The same process was carried out for the second treatment group. Direct Feedback (DF) group received two stages of direct feedback and wrote a new paragraph at last. A delayed new post test was conducted to investigate the longer term effects of feedback one month afterwards. To see examples of this type of corrective feedback see appendix 2. However, the procedure for the third treatment group was different. They were asked to write the first paragraph. They then were provided with indirect feedback. As the third stage came, they were provided with direct feedback as well as explicit corrective feedback (comments). In the end, they produced a new paragraph. Again, a month after the $4^{\text {th }}$ essay, a delayed new essay was composed as a delayed new one. The reason behind the two stages of feedback was making the researcher able to make a new way of providing feedback called IDECC which provided participants with a first stage of indirect feedback and then a second stage of direct one. To the last group, only placebo was exerted as telling them that their works just needed certain revisions. Table 1 shows the stages of providing feedback.

The process of data collection took 5 months, and was carried out in Isfahan, Iran. Prior to running the experiment, a pilot study was carried out. Then, students were randomly assigned and distributed into 4 groups.

Table 1. Experiment Design

\begin{tabular}{|c|c|c|c|c|c|}
\hline \multirow{2}{*}{ Groups } & \multicolumn{5}{|c|}{ Stages } \\
\hline & Essay 1 & Revised Essay 1 & Revised Essay 2 & Essay 2 & Delayed New Essay \\
\hline IF & IF & IF & $x$ & $x$ & $X$ \\
\hline DF & DF & DF & X & $x$ & $x$ \\
\hline IDECC & IF & DECC & $x$ & $X$ & $X$ \\
\hline NF & $\mathrm{X}$ & $\mathrm{X}$ & $\mathrm{X}$ & $X$ & $\mathrm{X}$ \\
\hline
\end{tabular}

$\left(^{\star}\right)$ Direct feedback with explicit comments, $(X)$ No feedback

\section{Results}

After data analysis, a repeated ANOVA was used to investigate the consistency of the frequency of errors in 5 groups. Also, the means of errors and standard deviations of each group in each stage of writing are presented in Table 2. Further, a figure is used to indicate the means of errors (Figure 1).

To find answer to the first research question which asked if the number of errors on across the writing stages are consistent, a repeated-measures ANOVA was exerted. Since there were five levels of independent variables (IF, DF, IDECC, NF), ), and five levels of dependent variables ( the frequency of errors in Essay 1, Revised Essay 1, Revised Essay 2, Essay 2, and a delayed new essay) the between subject and within subject methods were applied. Repeated measures ANOVA in table 3 below, indicated that the number of errors across all 5 writing stages in treatment groups are not consistent. According to the table, the significance level of the between group differences from Essay 1 to Revised Essay 1, Revised Essay 2, and Essay 2 was estimated at $(.002, .000, .000)$ respectively. This suggest that there has been obsereved significant difference among the frequency of errors in groups as a result of the provision of corrective feedback, and that the frequency of errors decreased in number from the first to the last stage of writing. In other words, giving the learners corrective feedback in all stages had significant effect on their writing accuracy and resulted in the decrease in the frequency of their errors. 
Table 2. Presentation of means of errors in each writing stage by different feedback groups

\begin{tabular}{|ll|c|c|c|c|c|}
\hline Group & & Essay 1 & Revised Essay 1 & Revised Essay 2 & Essay 2 & Delayed New Essay \\
\hline IF & Mean & 27.0476 & 10.2857 & 5.9048 & 11.8571 & 12.2857 \\
& N & 21 & 21 & 21 & 21 & 21 \\
& Std. Deviation & 10.80498 & 3.49489 & 3.01504 & 3.59563 & 3.49489 \\
DF & 26.5714 & 12.5238 & 3.6667 & 17.8571 & 18.3333 \\
& Mean & 21 & 21 & 21 & 21 & 21 \\
& N & 12.79286 & 6.46235 & 1.42595 & 5.60612 & 5.82523 \\
& Std. Deviation & 24.9048 & 14.7619 & 2.3810 & 8.6667 & 9.0952 \\
IDECC & Mean & 21 & 21 & 21 & 21 & 21 \\
& N & 9.12088 & 4.33480 & 1.07127 & 3.48329 & 3.31519 \\
& Std. Deviation & 25.8571 & 23.7619 & 22.1429 & 23.9524 & 24.4762 \\
NF & Mean & 21 & 21 & 21 & 21 & 21 \\
& N & 9.91103 & 9.28388 & 8.82772 & 9.18410 & 9.21748 \\
& Std. Deviation & 26.0952 & 15.3333 & 8.5238 & 15.5833 & 16.0476 \\
Total & Mean & 84 & 84 & 84 & 84 & 84 \\
& N & 10.58029 & 8.05004 & 9.26904 & 8.28151 & 8.32749 \\
& Std. Deviation & & & & \\
\hline
\end{tabular}

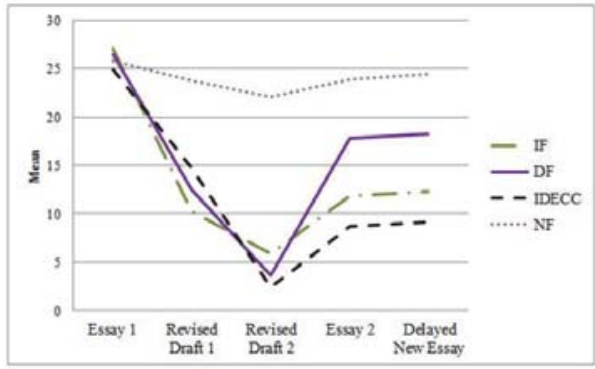

Figure 1. Mean of frequency of errors in each stage of essay writing

Table 3. Repeated ANOVA

\begin{tabular}{|ll|c|c|c|c|c|}
\hline & & Sum of Squares & df & Mean Square & $\mathrm{F}$ & Sig. \\
\hline \multirow{3}{*}{ Essay 1 } & Between Groups & 54.762 & 3 & 18.254 & .158 & .924 \\
& Within Groups & 9236.476 & 80 & 115.456 & & \\
& Total & 9291.238 & 83 & & & \\
& Between Groups & 539.524 & 3 & 179.841 & 5.272 & .002 \\
Revised Draft 1 & Within Groups & 2729.143 & 80 & 34.114 & & \\
& Total & 3268.667 & 83 & & & \\
& Between Groups & 2094.702 & 3 & 698.234 & 39.560 & .000 \\
Revised Draft 2 & Within Groups & 1412.000 & 80 & 17.650 & & \\
& Total & 3506.702 & 83 & & & \\
& Between Groups & 1156.607 & 3 & 385.536 & 12.755 & .000 \\
Essay 2 & Within Groups & 2418.095 & 80 & 30.226 & & \\
& Total & 3574.702 & 83 & & & \\
\hline
\end{tabular}

The second question aimed at investigating the longer effects of feedback on treatment groups. It also attempted to investigate the extent to which corrective feedback from teachers could be brought over to a delayed new piece of writing in response to a new prompt. In this test, a comparison was made to examine the impacts of three feedback strategies of teachers and the group with no corrective feedback. The number of errors on the first essay (essay 2) was compared to the one on the fifth (after the last essay writing of students as essay 2). In other words, this test was to investigate the carrying over of the treatment effect on a delayed new piece of writing. 
Four Samples T-Tests (paired) were run to address this question,. Since there were 4 paired t-tests, and in order to control for experiment-wise error, the alpha level had to be set at $p<.0125$. Such step included 84 students and their 168 essays. Data analysis by SPSS software indicated that in all three treatment groups, i.e. IF, DF, and IDECC, the number of errors in the delayed new post test was not significantly different from the post test (essay 2). Such a consistency between the numbers of errors in two groups along with considering the Table 5 suggests that the mean of the frequency of errors from Essay 2 and delayed new essay are to an extent consistent which further suggests that these two tests are to an extent the same as each other. The consistency between these two sets of scores and their means of errors highlights the point that the feedback was carried over to a longer term to a new essay.

\begin{tabular}{|c|c|c|c|c|c|c|c|c|}
\hline \multicolumn{9}{|c|}{ Paired Samples Test } \\
\hline & \multicolumn{5}{|c|}{ Paired Differences } & \multirow{3}{*}{$t$} & \multirow{3}{*}{\multicolumn{2}{|c|}{ df Sig.(2-tailed) }} \\
\hline & \multirow{2}{*}{ Mean } & \multirow{2}{*}{ Std. Deviation } & \multirow{2}{*}{ Std. Error Mean } & \multicolumn{2}{|c|}{$95 \%$ Confidence Interval of the Difference } & & & \\
\hline & & & & Lower & Upper & & & \\
\hline Pair 1 test4 - posttest & 1.01190 & 1.47668 & .16112 & .69145 & 1.33236 & 6.280 & 83 & .000 \\
\hline
\end{tabular}

\section{Discussion and Conclusion}

This research study aims at bridging the gap in the current literature on the effects of WCF provided by teachers on EFL learner writing accuracy. Since there is no consensus agreement on efficacy of provision of feedback on learner writing, the findings in this study have important implications to find out what exactly could be the proper answer to such a problem. In other words, the present study was conducted in order to examine different types of teacher WCF strategies with due concentration on English grammatical points such as English articles, verb agreement, and question forms. Such provision of feedback was conducted via email by the help of Microsoft Word Documment (i.e., features of track changes, and comments). 84 students of higher intermediate levels of three institutes of English higher intermediate took part in this study. They all took part in 5 stages of writing experiment consisting of the first writing task as Draft Essay 1 , making subsequent revisions two times as Revised Draft 1, and Revised Draft 2), and the last essay (Essay 2), and the delayed new essay to be examined regarding the effectiveness of teacher written corrective feedback.

Considering the first research question, researcher was to find the consistency in the mean of frequency of errors across the 5 writing stages and among the 4 feedback groups. The findings suggest the mean differences in number of errors between the treatment groups and the control one regarding the effect of feedback. Also, differences in the mean number of errors were found across first four stages of writing among Essay 1, both revisions, Essay 2. It could be concluded that feedback in the current study was influential in the decrease of errors regarding grammar in subsequent revised essays. Since there was a considerable significance between results of the two revision scores and the first essay, one can conclude that it is due to the provision of teacher WCF, while the decrease in the mean of frequency of errors in the final essay (Essay 2) shows that the WCF could have a long lasting effect on students' writings.

In comparison to treatment groups which revealed that they could outperform the control one in immediate and later draft revisions no significant difference could be observed from the results of control group in order to claim that they have made a significant difference in their works results; only a slight and inconsiderable decrease was observed. The third feedback group called IDECC which received feedback in two separate segments, one via indirect feedback in the first stage of provision of feedback and one after that via direct one along with explicit corrective comments, outperformed the other two feedback groups which received one type of feedback in both their two revision stages. The IDECC group of treatment indicated a decrease of the frequency of errors by $90.5 \%$ in Revised Essay 1 as in comparison to the IF one (78.19\%), the DF counterpart (86.3\%), and obviously the NF group which was under control (14.4\%). Findings of the study propose that provision of feedback in a written form from teachers, irrespective of the type of feedback, was perceived as influential in decrease of the frequency of errors on intended grammatical items. Such results are in keeping with the results obtained from studies conducted by Abadikhah and Ashoori (2012), and Ahmadi, Maftoon, and Gholami (2012).

To more meticulously compare differences between the IF and DF groups in their two immediate revision stages after being provided with two levels of teacher WCF, differences were examined and it was found that the DF one performed more accurately than their counterparts in IF group. This is justifiable due to the fact that the DF group received not only the signals regarding place of the errors, but also the correct and accurate form of the errors. However, the IF group did not receive the correct form, and just received certain points regarding the existence of an error in the written text. However, regarding the long term effects of provision of feedback one month after the last feedback it was 
theoretically expected that the IF group would outperform the DF one in the final essay which became as a real one. This is due to the assumption that indirect feedback provides learners with more opportunities for learning deeply in the long term than the direct feedback. Once learners are given indirect feedback, they are subconsciously cognitively challenged to think more deeply on the clues they are given by their teachers, are involved more in figuring out the correct forms since their focus was on the errors and grammatical forms, and are engaged, and asked to do the process of problemsolving in which some experts believe learners are more benefited in regard to the long-term learning improvement (Ahmadi, Maftoon, and Gholami 2012).

The third group of treatment which was IDECC outperformed all the other ones in regard to the grammatical accuracy in both stages of revisions and in the new essay. It has been supported by previous research studies stating that the provision of explicit corrective comments along with description of what the grammatical rule is, or with metalinguistic information, is of importance and beneficial for learners in long term, which can make learners more attentive to grammar and/or engage them in the process of problem-solving in order to find the correct form by themselves (Abadikhah \& Ashoori 2012, Alvarez, Espasa, \& Guasch 2012, Azizi, Behjat, \& Sorahi 2014, Jokar \& Soyoof 2014, Rahimi \& Asadi 2014). Moreover, once the learners are provided with indirect feedback and direct one (subsequently) and explicit corrective comments, as was done in IDECC, they could more effectively correct their grammatical errors than the other strategies consisting of only direct or indirect feedback. This is true for both the second revisions and final essay writing. Considering the results of this study, there is more evidence in line with the effectiveness of teacher corrective feedback, more specifically along with metalinguistic explanation in the form of ECC on grammatical rule, in improvement of learners' grammatical accuracy in writing.

The second research question sought to find the answer to the question the extent to which the provision of teacher WCF could have a longer-term effect on learner production of a delayed new essay errors committed by participants in the final essay, almost 4 weeks after the last essay production. To find the proper answer, 4th written essays and the delayed new ones were compared in order to identify the long term effects of WCF by teachers. Findings suggest that the mean of frequency of grammatical errors being examined in the present study were consistent in all three groups while there was none in the control group or at least it wasn't considerable enough. Such findings may imply that provision of WCF by teachers have a more lasting impact in the sense that it helps reducing the grammatical errors when new essays were written.

Another conclusion which could be drawn out of such findings is that provision of indirect feedback and the subsequesnt direct feedback along with explicit corrective comments regarding grammatical issues seems to have had more impact on participants' writings in decreasing their errors while they were writing the fourth essay (Essay 2), especially, when it is compared to other groups which employed only one method of feedback provision. This may suggest that the impacts of providing feedback are transferable to the subsequent levels in writing new essays. Such findings are in line with the findings of previous studies by Abadikhah and Ashoori (2012). Rahimi and Asadi (2014) argued that "provision of some types of explicit corrective comments or metalinguistic explanations are influential in language learners' improvement of their grammatical accuracy in the long run".

\section{References}

Abadikhah, S., \& Ashoori, A. (2012). The Effect of Written Corrective Feedback on EFL Learners' Performance after Collaborative Output. Journal of Language Teaching and Research.

AbuSeileek, A., \& Abualsha'r, A. (2014) Using peer computer-mediated corrective feedback to support EFL learners' writing. Language Learning \& Technology 18(1), 76-95.

Ahmadi, D., Maftoon, P., \& Gholami Mehrdad, A. (2012). Investigating the effects of two types of feedback on EFL students'. Procedia Social and Behavioral Sciences.

Alvarez, I., Espasa, A., \& Guasch, T. (2012). The value of feedback in improving collaborative writing assignments in an online learning environment. Studies in Higher Education.

Azizi, M., Behjat, F., \& Sorahi, M. (2014). Effect of metalinguistic teacher corrective feedback on writing performance of Iranian EFL learners. International Journal of Language and Linguistics.

Bitchener, J. (2012). A reflection on 'the language learning potential' of written CF. Journal of Second Language Writing.

Ebadi, E. (2014). The Effect of Focused Meta-linguistic Written Corrective Feedback on Iranian Intermediate EFL Learners" Essay Writing Ability. Journal of Language Teaching and Research.

Ellis, R., Sheen, Y., Murakami, M., \& Takashima, H. (2008). The effects of focused and unfocused written corrective feedback in an English as a foreign language context. System, 36, 353-371.

Ferris, D. R. (1999). The case for grammar correction in L2 writing classes: A response to Truscott (1996). Journal of Second Language Writing, 8, 1-11. 
Guénette, D. (2007). Is feedback pedagogically correct? Research design issues in studies of feedback on writing. Journal of Second Language Writing, 16, 40-53.

Jokar, M., \& Soyoof, A. (2014). The Influence of Written Corrective Feedback on Two Iranian Learners' Grammatical Accuracy. Procedia - Social and Behavioral Sciences.

Kepner, C. G. (1991). An experiment in the relationship of types of written feedback to the development second-language writing skills. The Modern Language Journal, 75(3), 305- 313.

Rahimi, M., \& Asadi, E. (2014). Effect of Different Types of Written Corrective Feedback on Accuracy and Overall Quality of L2 Learners' Writing. European Journal of Academic Essays.

Rob, T., Ross, S., \& Shortreed, I. (1986). Salience of feedback on error and its effect on EFL writing quality. TESOL Quarterly, 20(1), 8395.

Semke, H. D. (1984). Effects of the red pen. Foreign Language Annals, 17, 195-202.

Sheppard, K. (1992). Two feedback types: Do they make a difference? RELC Journal, 23(1), 103-110.

Truscott, J. (1996). The case against grammar correction in L2 writing classes. Language Learning, 46, 327-369.

\section{Appendix 1}

Instances of Providing Feedback (IF)

\section{Feedback Focus:}

1. Article Use (e.g., A/An, The)

2. Verb Agreements (Like third person singular S)

3. Question Forms (Like Deletion of Auxiliary Verbs)
Yellow highlight

Bright Green highlight

Turquoise highlight

\section{Unrevised Essay}

My parents are one of those who emphasizes on learning English then I studied English when I was eight years old in the famous institute which had many experienced teachers and also It had the laboratory with many facilities in an attempt to help the learners to learn English easily. The question here is how effective is that? Although we had some an English course at school, those are not that much practical. Since our teachers only taught Grammars and they did not force us to speak and used these grammar points orally. As a result many students who did not go to extra English classes, they could not speak English well because they did not have a chance to use what they had learnt or to find out how much do they understand? To my point of view if a person cannot speak well he cannot write correctly either and it is very important to let the students speak and correct them appropriately that not only do they learn the correct form, but also never forget it.

\section{First feedback from teacher (Feedback 1)}

My parents are one of those who emphasizes on learning English then I studied English when I was eight years old in the famous institute which had many experienced teachers and also It had the laboratory with many facilities in an attempt to help the students to learn English easily. The question here is how effective is that? Although we had some an English course at school, those are not that much practical. Since our teachers only taught Grammars and they did not force us to speak and used these grammar points orally. As a result many students who did not go to extra English classes, they could not speak English well because they did not have a chance to use what they had learnt or to find out how much do they understand? To my point of view if a person cannot speak well he cannot write correctly either and it is very important to let the students speak and correct them appropriately that not only do they learn the correct form, but also never forget it.

\section{Second feedback from the teacher (Feedback 2)}

My parents are one of those who emphasized on learning English then I studied English when I was eight years old in a famous institute which had many experienced teachers and also It had a laboratory with many facilities in order to help all students to learn English easily. The question here is how effective they are? Although we had some the English course at school, the ones that are not that much practical. Since our teachers only taught Grammars and they did not force us to speak and used these grammar points orally. As a result many students who did not go to extra English classes, they could not speak English well because they did not have a chance to use what they had learnt or to find out how much do they understand? To my point of view if a person cannot speak well he cannot write correctly either and it is very important to let all students speak and correct them appropriately that not only do they learn the correct form, but also never forget it.

\section{Appendix 2}

Instances of Providing Feedback (DF)

\section{Feedback Focus:}

a. Article Use (e.g., A, An, The)

b. Verb Agreements (Like third person singular S)

C. Question Forms (Like Deletion of Auxiliary Verbs)
Yellow highlight

Bright Green highlight

Turquoise highlight 


\section{Unrevised Essay}

The teacher is very important in the English learning. When I was a child and I wanted to study English I had a teacher who was strict man and mean and it made. It was very difficult for me to like him. And it was one of the reason why I didn't continue. I remember that one time when I was some minutes late he didn't let me to go to the class and told me that he would give me a bad score for that. It was a very bad experience.

\section{First feedback from teacher (Feedback 1)}

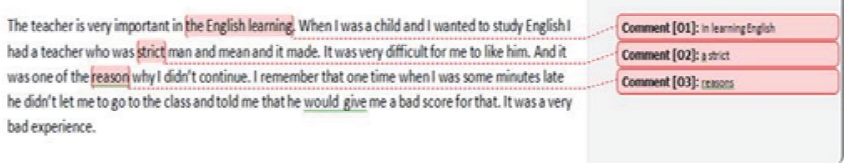

3. Second feedback from teacher (Feedback 2)

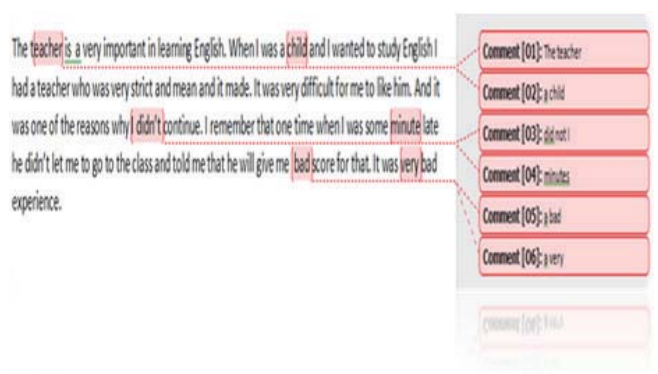


